\title{
Initiation of Aggregation by Dictyostelium discoideum in Mutant Populations Lacking Pulsatile Signalling
}

\author{
By PETER M. GLAZER AND PETER C. NEWELL* \\ Department of Biochemistry, University of Oxford, South Parks Road, \\ Oxford OXI 3QU, U.K.
}

(Received 13 November 1980; revised 21 January 1981)

\begin{abstract}
The proportion of a wild-type population capable of initiating aggregation centres in starving fields of Dictyostelium discoideum was investigated using mixed populations of a few wild-type amoebae and a large excess of a mutant incapable of initiating aggregation signals but fully capable of responding to them. For this purpose an aggregation-deficient mutant (designated NP160) was isolated that showed high sensitivity to wild-type strains in synergy tests. This mutant formed normal cell-surface cyclic AMP receptors and phosphodiesterases and was fully capable of chemotaxis to cyclic AMP. Although it had an active adenylate cyclase and formed cyclic AMP, it was deficient in the pulsatile regulation of this enzyme and did not initiate or relay pulsatile cyclic AMP signals and did not form cell adhesive 'contact sites A' unless given artificial cyclic AMP pulses. When synergistic mixtures of this mutant and the wild-type were made, the mutant formed fruiting bodies at frequencies indicating that up to 1 in 5 of the wild-type cells could initiate aggregation centres when present at a ratio of between 1 in 500 and 1 in 10000 of the mixed amoebal population.
\end{abstract}

\section{INTRODUCTION}

Whether the amoebae that initiate the aggregation phase of Dictyostelium form a genetically distinct subpopulation has been a matter of controversy for many years. Although it is now commonly stated that cells capable of initiation are not genetically different but arise at random in a starving population, no conclusive evidence for this notion has been reported.

The idea of a genetically distinct population of 'Initiator' (or 'I') cells was first proposed by Sussman \& Noel (1952) and evidence for their existence was presented by Ennis \& Sussman $(1958 a)$. I cells were reported to be morphologically distinct from other cells, being two to three times larger in diameter, and they were found at a fixed proportion of about 1 cell in 2000 , even in the pre-aggregative growth phase. The I cells could be correlated with the sites at which aggregation centres formed and it was found that one aggregate was formed for approximately every 2200 cells of the wild-type in agreement with the observed frequency of $I$ cells. Konijn \& Raper (1961), however, questioned the existence of a special cell type occurring at a definite proportion that was exclusively capable of autonomy. They found that aggregates almost always developed in populations even as small as 100 cells, and they were unable to detect any morphologically distinct cells among these populations. They did observe some larger-than-average cells, but they could not correlate the presence of these cells with aggregation. They proposed the existence of a single population of cells with a continuous size distribution instead of the discontinuous distribution of initiator and responder cells described by Ennis \& Sussman (1958a). Gerisch (1961) confirmed the capacity of small, isolated populations to aggregate by showing that aggregation occurred regularly in populations of 100 to 200 amoebae. Like Konijn \& Raper (1961), he was unable to find a correlation between cell morphology and aggregation, and he concluded that if I cells exist, 
they must occur at least twenty times as frequently as Sussman and his co-workers proposed.

Subsequently, the question of the nature of the autonomous cell was taken up again by Raman et al. (1976) who sought to quantify the intrinsic probability that a given cell will express autonomy as a function of the time of development, the size of total cell population, and the cell density. By observing small populations of cells on agar carefully controlled for these parameters, and by measuring the absence rather than the occurrence of aggregation (where aggregation occurs it is impossible to say how many autonomous cells were present), they found that the probability of autonomy saturates by $24 \mathrm{~h}$ after starvation and is significantly non-zero only after about 8 to $10 \mathrm{~h}$. They also showed that the saturation value for the probability of autonomy was inversely proportional to the total cell population for a fixed cell density. The highest value found for this probability was $10^{-2}$, in agreement with the data of Konijn \& Raper (1961), but they were also able to reproduce the numerical results of Ennis \& Sussman $(1958 a, b)$ at the appropriate cell density and population. Raman (1976) argued that such evidence concerning aggregation in small populations of cells cannot resolve whether or not there exists a special subset of cells predetermined to be exclusively capable of autonomy.

One way to resolve this question would be to look at smaller and smaller populations of cells. But aggregation among wild-type cells is infrequent in populations below about 100 cells, and aggregation of a single cell is an absurd notion. Therefore, the question cannot be answered by looking only at homogeneous cell populations. However, as Raman (1976) suggested, it 'can perhaps be resolved only through a detailed study of mixed populations of wild-type amoebae and mutants that do not show autonomy', for in such mixtures the capacity of individual wild-type cells to initiate aggregation can theoretically be measured. It was this experimental approach that was adopted for the work described in this paper.

For such an investigation it was necessary to have an aggregation-deficient mutant which could not generate autonomously signalling cells but which could show synergism with signalling-competent wild-type cells and which possessed sufficient sensitivity to aggregate when initiated by very small numbers of the wild-type. Early work by Sussman (1952) and Ennis \& Sussman $(1958 b)$ with synergistic mixtures of wild-type and aggregation-defective mutants used mutant strains that lacked this sensitivity. To be sensitive to isolated wild-type cells the mutant would have to be normal in forming cell-surface cyclic AMP receptors and phosphodiesterases and be chemotactically competent. This combination of characteristics is not commonly found in non-aggregating strains and does not, for example, fit any of the categories of aggregation mutants of Darmon et al. (1977) or Juliani \& Klein (1978). After initial screening, strain NP160 was selected for further study as it showed an unusual ability to synergize not just with wild-type strains but also with many mutant strains that could achieve the loose cell aggregate stage in development. Furthermore, spores of the fruiting bodies produced by synergism of NP160 with the wild-type yielded amoebal populations reflecting the original proportion of strains mixed, whereas for other mutants tested the wild-type was normally favoured by a factor of $10^{2}$ to $10^{4}$. Mutant NP160 seemed, therefore, to be a good prospect for the desired mutant, as was confirmed in the biochemical and genetic work outlined below.

\section{METHODS}

Media and chemicals. The composition and methods of preparation of nutrient (SM) and selective media, and the chemicals used were as described previously (Mosses et al., 1975; Ratner \& Newell, 1978).

Strains. All Dictyostelium discoideum strains used are derivatives of NC4 (Raper, 1935). Strain M28, originally obtained from Dr Eugene Katz, S.U.N.Y., Stoneybrook, N.Y., U.S.A., is a developmentally competent strain that bears the genetic markers $b w n A$ (production of brown pigment), $t s g E$ (temperature sensitive for growth) and $s p r A$ (round spores) (Katz \& Sussman, 1972). Strain NP160 was isolated as a spontaneous mutant of strain M28 that was unable to aggregate.

Maintenance of stocks. All strains of $D$. discoideum were grown at $22{ }^{\circ} \mathrm{C}$ in the dark on SM agar in association with a cobalt-resistant mutant of Klebsiella aerogenes designated OXF1 (Williams \& Newell, 1976). Working 
stocks were maintained by weekly clonal passage in association with bacteria. The primary stock of strain NP160 was kept as spores produced in synergism with strain M28. The mixture of NP160 spores and M28 spores was maintained desiccated in silica gel at $4{ }^{\circ} \mathrm{C}$. A stock of M28 spores alone was also kept in silica gel, and a secondary stock of NP160 amoebae, derived from a single clone from the above mixture of spores, was stored frozen in horse serum containing $5 \%(\mathrm{v} / \mathrm{v})$ dimethyl sulphoxide in plastic straws immersed in liquid nitrogen.

Parasexual genetic manipulations. These were carried out using previously described methods (Williams et al., 1974; Ratner \& Newell, 1978; Ross \& Newell, 1979).

Cyclic AMP binding assay. The assay used was that described by Green \& Newell (1975), except the Nuclepore polycarbonate filters were used instead of Millipore membrane filters (Mullens \& Newell, 1978). For the time course of cyclic AMP binding, cells were harvested, washed free of bacteria, resuspended at $1 \times 10^{7}$ amoebae $\mathrm{ml}^{-1}$ in $17 \mathrm{mM}-\mathrm{K}_{2} \mathrm{HPO}_{4} / \mathrm{KH}_{2} \mathrm{PO}_{4}$ buffer $\mathrm{pH} 6 \cdot 1$, and then shaken at $22^{\circ} \mathrm{C}$ in a rotary shaker. At intervals, samples of the cell suspensions were withdrawn and washed twice with $50 \mathrm{mM}$ ice-cold $\mathrm{K}_{2} \mathrm{HPO}_{4} / \mathrm{KH}_{2} \mathrm{PO}_{4}$ buffer $\mathrm{pH} 6 \cdot 2$, and readjusted to $10^{7}$ cells $\mathrm{ml}^{-1}$ for the assay, which was performed in duplicate.

Assay of membrane-bound and extracellular phosphodiesterase. Phosphodiesterase activity was assayed using the method of Ross \& Newell (1981) which is a modified form of the chromatographic assay of Malchow et al. (1972).

Test for chemotaxis. Agar plates containing $2 \%(\mathrm{w} / \mathrm{v})$ Oxoid agar and $25 \mathrm{mM}-\mathrm{K}_{2} \mathrm{HPO}_{4} / \mathrm{KH}_{2} \mathrm{PO}_{4}$ buffer pH 6.0 were made up with and without cyclic AMP. For each strain, the series of plates included a control plate with no cyclic AMP and plates containing cyclic AMP at concentrations of $10 \mathrm{nM}, 100 \mathrm{nM}, 1 \mu \mathrm{M}, 10 \mu \mathrm{M}$ and $100 \mu \mathrm{M}$. Cells were harvested, washed free of $K$. aerogenes and resuspended in $17 \mathrm{mM}-\mathrm{K}_{2} \mathrm{HPO}_{4} / \mathrm{KH}_{2} \mathrm{PO}_{4}$ buffer pH 6.1 at $2 \times$ $10^{7}$ cells $\mathrm{ml}^{-1}$. Fifteen drops of about $20 \mu \mathrm{l}$ each from the appropriate cell suspensions were put down in a grid on to each of the plates. The plates were kept at $22^{\circ} \mathrm{C}$ for $7 \mathrm{~h}$ and then examined for evidence of chemotaxis. Chemotaxis was indicated by increased outward movement of the cells from their original small drops, as compared with the cells on the control plates lacking attractant. Cells in the drops on the unsupplemented agar tended to stay within the area of the small drop, but in the plates containing cyclic AMP, spatial gradients of cyclic AMP were created around the small drops by the action of the extracellular phosphodiesterase produced by the cells. If the cells were chemotactically competent, they responded to these gradients by moving outward from the confines of their small drop. Hence, a positive result in this test indicated that the cells were capable of both chemotaxis and of extracellular phosphodiesterase production. A negative result meant that the cells lacked one or both of these capacities.

Light scattering in cell suspensions. Cells were harvested, washed free of bacteria and resuspended in $17 \mathrm{mM}-\mathrm{K}_{2} \mathrm{HPO}_{4} / \mathrm{KH}_{2} \mathrm{PO}_{4}$ buffer pH 6.1 at $2 \times 10^{7}$ cells $\mathrm{ml}^{-1}$. The cell suspension was shaken at $22^{\circ} \mathrm{C}$, and at various times during development $30 \mathrm{ml}$ samples were withdrawn. Cells were washed twice with phosphate buffer and finally resuspended in $3 \mathrm{ml}$ of buffer, at about $2 \times 10^{8}$ cells $\mathrm{ml}^{-1}$. This suspension was placed in a $3 \mathrm{ml}$ spectrophotometer cuvette with a wax slope in the bottom (Gerisch \& Hess, 1974). Oxygen was bubbled through the suspension in the cuvette through two syringe needles. Cyclic AMP was added to the cuvette in $100 \mu \mathrm{l}$ quantities from solutions containing approximately 30 times the final concentration of cyclic AMP desired. Changes in the absorbance at $405 \mathrm{~nm}$ of the cell suspension were monitored using a recording spectrophotometer.

Cyclic AMP assays. The nucleotide was assayed using the cyclic AMP assay kit from Amersham. Cells were harvested, washed free of bacteria, resuspended at $2 \times 10^{7}$ cells ml ${ }^{-1}$ in $17 \mathrm{mM}-\mathrm{K}_{2} \mathrm{HPO}_{4} / \mathrm{KH}_{2} \mathrm{PO}_{4}$ buffer $\mathrm{pH} 6.1$, and shaken at $22^{\circ} \mathrm{C}$. At intervals, $10 \mathrm{ml}$ samples were withdrawn and the cells were separated from the supernatant by centrifugation for $3 \mathrm{~min}$. The cell sediment was resuspended to a final volume of $300 \mu \mathrm{l}$ in Tris/EDTA buffer. From this suspension, four $35 \mu \mathrm{l}$ samples were taken at $90 \mathrm{~s}$ intervals and added to a microfuge tube already containing $20 \mu \mathrm{l}$ of $4 \mathrm{M}$-perchloric acid and $5 \mu \mathrm{l}$ of universal indicator; the pH was adjusted to 7.5 with $4 \mathrm{M}-\mathrm{KOH}$. The samples were collected in four parts at $90 \mathrm{~s}$ intervals in order to average fluctuations in cyclic AMP pool levels, and they were mixed with perchloric acid so that cellular reactions, especially phosphodiesterase activity and continued cyclic AMP production, would be uniformly halted. After neutralization with $\mathrm{KOH}$, each sample was centrifuged for $2 \mathrm{~min}$. The supernatant, which contained the cyclic AMP, was assayed in duplicate: $50 \mu$ supernatant was placed in each of two separate microfuge tubes in an ice bath and to each tube was added $50 \mu$ of the cyclic $\left[{ }^{3} \mathrm{H}\right] \mathrm{AMP}$ solution (containing $0.9 \mathrm{pmol}$ ) and $100 \mu \mathrm{l}$ of binding protein solution, both from the assay kit. After mixing, the tubes were left at $4^{\circ} \mathrm{C}$ for $2 \mathrm{~h}$, and then $100 \mu \mathrm{l}$ of activated charcoal suspension was added to each tube. Each tube was shaken thoroughly, left at $4{ }^{\circ} \mathrm{C}$ for exactly $2 \mathrm{~min}$ and then centrifuged for $2 \mathrm{~min}$ to separate the charcoal fraction. A $200 \mu \mathrm{l}$ portion of the supernatant was mixed in a scintillation vial with $3 \mathrm{ml}$ of toluene/triton/2,5-diphenyloxazole scintillant, and the radioactivity in each vial was recorded. Serial dilutions of a standard cyclic AMP solution were treated in the same way as the unknowns.

Assay of contact sites $A$. Cells were harvested, washed free of bacteria and resuspended in $17 \mathrm{M}$ $\mathrm{K}_{2} \mathrm{HPO}_{4} / \mathrm{KH}_{2} \mathrm{PO}_{4}$ buffer $\mathrm{pH} 6.1$ at $1 \times 10^{7}$ cells $\mathrm{ml}^{-1}$. For each strain the cell suspension was divided into two parts: the first was left stirring at $22{ }^{\circ} \mathrm{C}$, while the second $50 \mathrm{ml}$ portion was stirred at $22{ }^{\circ} \mathrm{C}$ and treated with cyclic AMP pulses at $5 \mathrm{~min}$ intervals starting $1.5 \mathrm{~h}$ after starvation. Pulses were delivered in the form of $27 \mu \mathrm{ldrops}$ of a $185 \mu \mathrm{M}$-cyclic AMP solution, adding $5 \mathrm{nmol}$ cyclic AMP per pulse to a final concentration of approximately 
$100 \mathrm{nM}$. The drops were generated by carefully controlling the flow of a cyclic AMP solution from a large reservoir in a separatory funnel through clamped rubber tubing and a drawn out Pasteur pipette. At each time point, two $0.1 \mathrm{ml}$ samples of each suspension were taken to assay for the formation of EDTA-resistant cell contacts. To one of these samples, $0.5 \mathrm{ml}$ of a $0.01 \mathrm{M}$-EDTA solution was added; the other received $0.5 \mathrm{ml}$ of buffer alone. Both mixtures were shaken vigorously for $15 \mathrm{~s}$ in order to dissociate possible existing agglutinates. The mixtures were left for $2 \mathrm{~min}$ and then examined by microscope for the presence of cell clumps.

Synergism of strains M28 and NP160. Square agar chips of area $2.25 \mathrm{~cm}^{2}$ were cut from $2 \%$ agar plates containing $25 \mathrm{mM}-\mathrm{K}_{2} \mathrm{HPO}_{4} / \mathrm{KH}_{2} \mathrm{PO}_{4}$ buffer pH 6.2. Freshly harvested cells of M28 and NP160 were carefully spread on to the agar chips to the appropriate density. Volumes of between 1 and $50 \mu l$ of appropriately diluted cell suspensions were spread; all agar chips received a total of about 45000 cells, made up of different proportions of M28 and NP160 cells. They were incubated at $22{ }^{\circ} \mathrm{C}$ under controlled humidity and monitored for $5 \mathrm{~d}$ for the development of fruiting bodies.

\section{RESULTS}

\section{Genetic locus of strain NP160}

Mutant NP160 arose spontaneously in the developmentally proficient strain M28. The mutant produced clones which grew at the normal growth rate on agar plates inoculated with lawns of $K$. aerogenes but failed completely to aggregate and consequently had a flat morphology inside the clonal growth ring. The mutation (agg-87), which was stably inherited, was located on linkage group IV by its segregation pattern from diploids DP1028 and DP1029 constructed from NP160 and the tester strains XP95 and XP92, respectively (Table 1). The spontaneous occurrence and simple pattern of segregation indicated that the mutation was probably at a single locus.

Complementation studies in diploids constructed with other aggregation-deficient strains showed that the mutation was in a different complementation group from previously published mutations and the locus was, therefore, designated aggL.

\section{Formation of the chemosensory apparatus}

Cyclic AMP receptors. The ability of strain NP160 to form cell-surface cyclic AMP receptors was tested by the binding of cyclic $\left[{ }^{3} \mathrm{H}\right]$ AMP to amoebae and separating amoebae from the unbound radioactivity using the membrane filter technique (Green \& Newell, 1975; Mullens \& Newell, 1978). The degree of binding (Fig. 1) found for NP160 was similar to that for strain M28 and clearly showed an adequate degree of binding in the mutant for efficient cyclic AMP detection. Analysis using Scatchard plots showed normal formation of both high and low. affinity forms of the receptor.

Phosphodiesterases. When phosphodiesterase activity was measured both in the extracellular supernatant (Fig. 2) and associated with the cell-surface membranes (Fig. 3) the mutant was again found to resemble the parental strain M28 over the first 8 to $10 \mathrm{~h}$ of development. The amount of phosphodiesterases produced by NP160 is sufficient for signal destruction (needed as part of the signal detection system) and indeed is slightly higher than for some other parental types that are aggregation competent.

Chemotaxis. The chemotactic ability of NP160 was assayed in two ways. Firstly, the movement of amoebae was observed in a drop of cells on buffered non-nutrient agar containing cyclic AMP at a concentration of $10 \mathrm{nM}$ to $100 \mu \mathrm{M}$. Over a period of $7 \mathrm{~h}$ both M28 and NP160 were seen to move outward as a ring. This test not only demonstrated the chemotactic ability of the mutant but also confirmed the existence of a functional phosphodiesterase, as the movement is a response to a cyclic AMP gradient created by the phosphodiesterase of the cells in the drop (Bonner et al., 1969). The second chemotactic test made use of the changes in optical properties of starving amoebae in suspension in response to pulses of cyclic AMP (Gerisch \& Hess, 1974). During the response the absorbance of the cell suspension decreases transiently in a characteristic manner that is correlated with chemotactic movement (Ross \& Newell, 1981). The sensitivity to pulses of cyclic AMP 


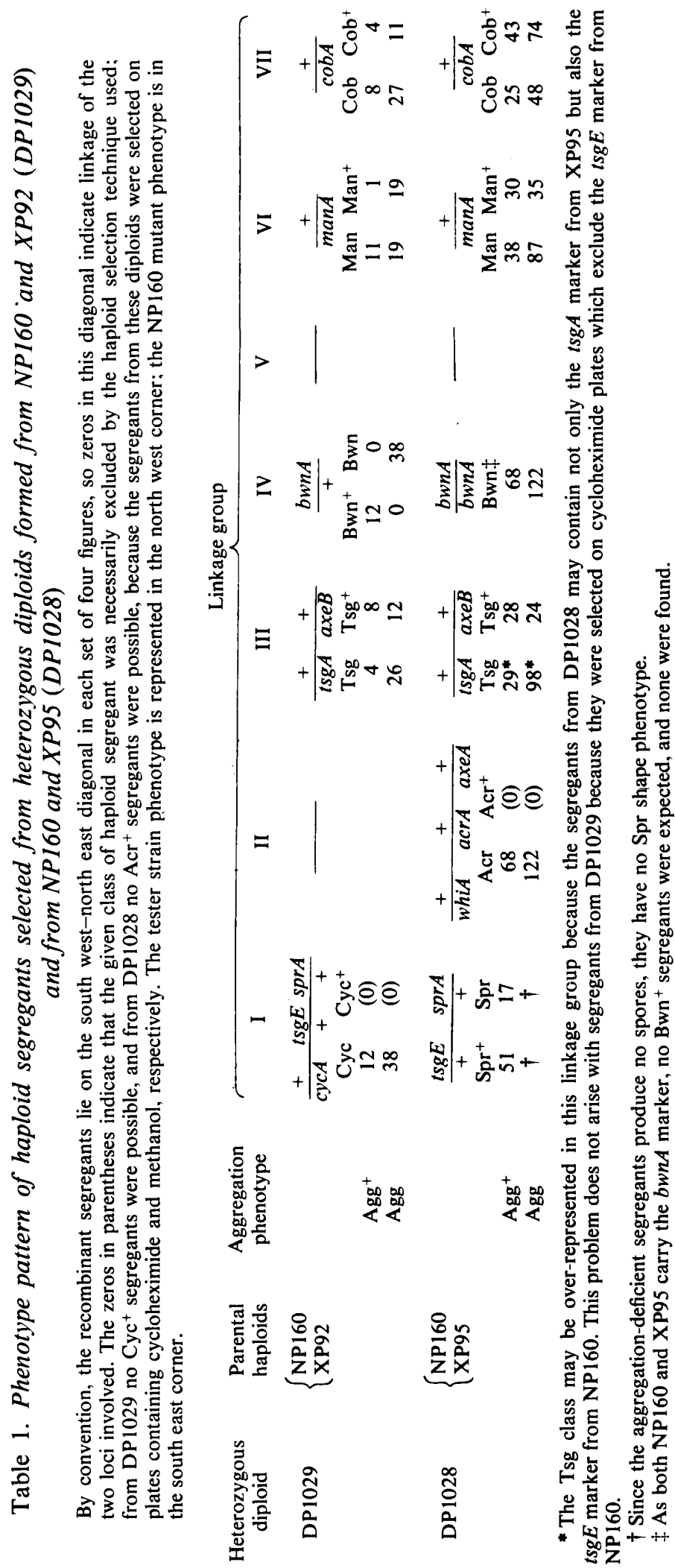




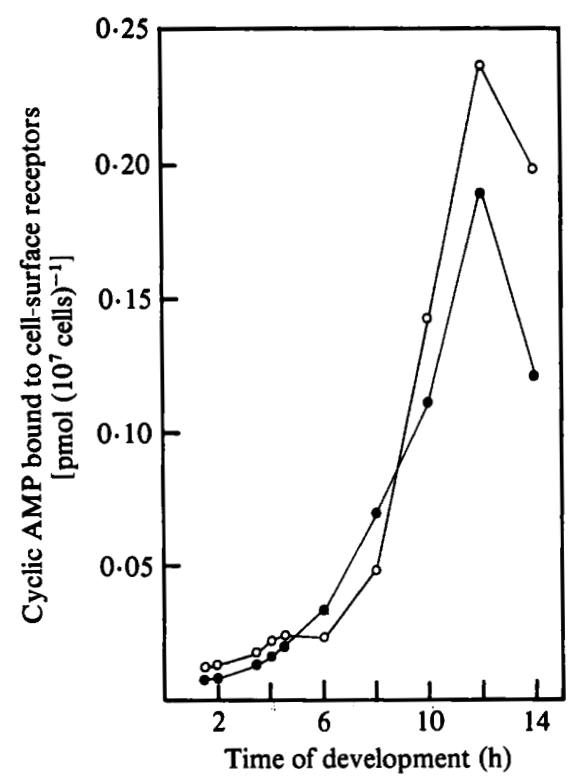

Fig. 1. Time course of cyclic AMP binding to whole cells of parental strain M28 (O) and mutant NP160 (๑).



Fig. 2

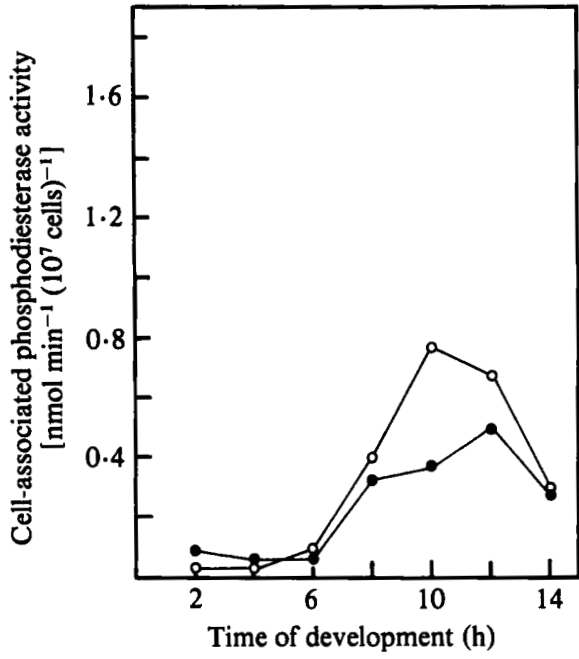

Fig. 3

Fig. 2. Activity of extracellular cyclic AMP phosphodiesterase during the first $14 \mathrm{~h}$ of development of parental strain M28 (O) and mutant NP160 (O) in starving cell suspensions.

Fig. 3. Activity of cell-associated cyclic AMP phosphodiesterase during the first $14 \mathrm{~h}$ of development of parental strain M28 (O) and mutant NP160 (O) in starving cell suspensions.

between $10 \mu \mathrm{M}$ and $100 \mathrm{pM}$ was determined for NP160 and was found to be almost identical to that for the parental strain M28 (Fig. 4). The refractory period for the chemotactic response was also investigated by using two pulses of cyclic AMP given at intervals of 2 min or a few seconds apart. As shown in Fig. 5, the response for a second pulse 




Fig. 4. Light scattering responses of mutant NP160 and parental strain M28 produced by pulses of cyclic AMP. Oxygenated suspensions of starving amoebae $\left(2 \times 10^{8} \mathrm{ml}^{-1}\right)$ were monitored for absorbance at $405 \mathrm{~nm}$ after $9 \mathrm{~h}$ of development at $22^{\circ} \mathrm{C}$. The effect of pulses of cyclic AMP from $10 \mu \mathrm{M}$ to $100 \mathrm{pM}$ (final concentration) was recorded.

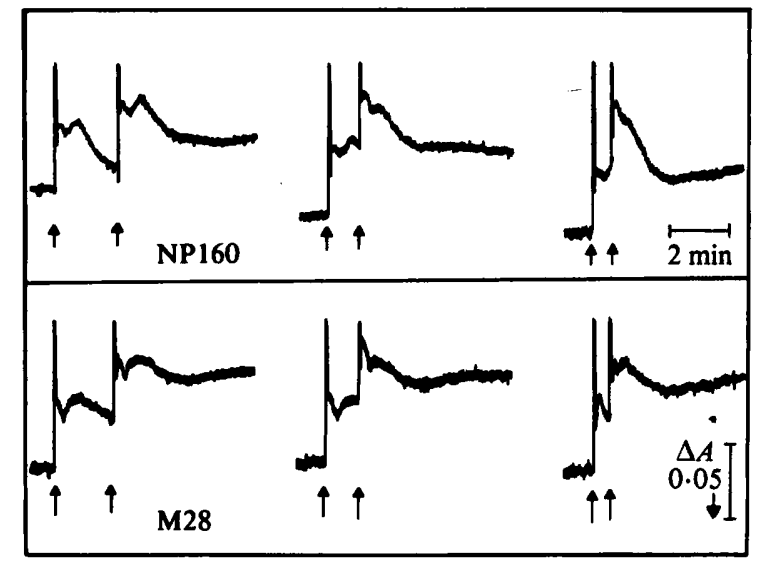

Fig. 5. Light scattering responses of mutant NP160 and parental strain M28 to two 100 nM pulses of cyclic AMP (final concentration) delivered with a short interval between them. Conditions were as described in Fig. 4. The cyclic AMP pulses were delivered with $2 \mathrm{~min}, 1 \mathrm{~min}$ and $30 \mathrm{~s}$ intervals at times indicated by the arrows.

could be seen in both strains even if this was given only $30 \mathrm{~s}$ after the first. Clearly this facet of the chemosensory apparatus is not deficient.

Cyclic AMP formation. The basal cellular concentration of cyclic AMP was measured using a binding assay to determine whether or not the mutant possessed active adenylate cyclase. The results (Fig. 6) indicate that the pattern of cyclic AMP concentration was similar in NP160 and M28 at early times of starvation but after 6 to $7 \mathrm{~h}$ the parental strain showed a considerably higher concentration. Although the assay could not detect the individual fluctuations of cyclic AMP that would be expected in a signalling-competent strain, these fluctuations would tend to increase the average concentration observed by this method, thereby producing the increase in the cyclic AMP concentration observed in M28. Direct assay of adenylate cyclase (kindly performed by Dr M. B. Coukell, using the methods of Coukell \& Chan, 1980) confirmed that the mutant possessed the basal activity of this enzyme and that this increased during the first $6 \mathrm{~h}$ of development in NP160 to approximately $50 \%$ of 


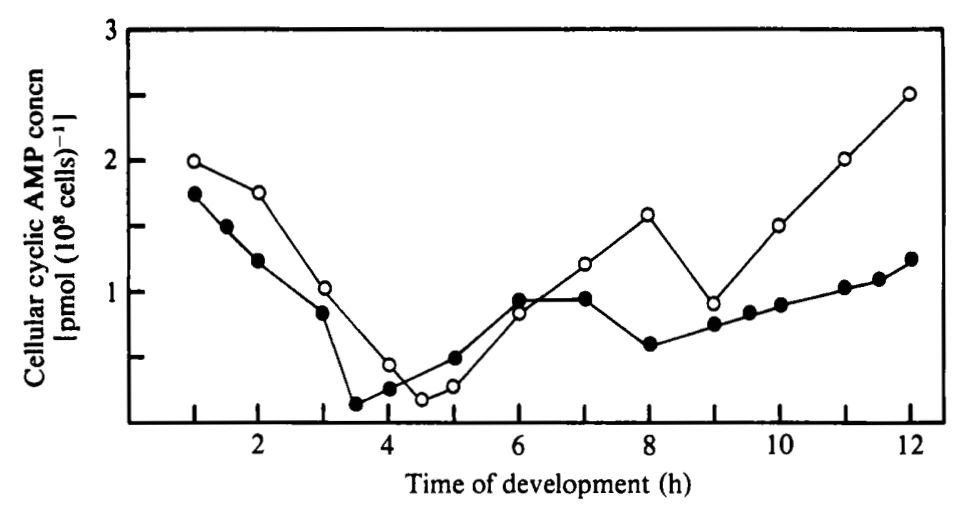

Fig. 6. Cellular cyclic AMP concentrations in parental strain M28 (O) and mutant NP160 (O) during the first $12 \mathrm{~h}$ of development in cell suspension. These curves represent the average of two separate experiments.

the activity of the parental strain. INP160 activity rose from 0.3 units (mg protein) ${ }^{-1}$ at the end of the growth phase to 9 units (mg protein) ${ }^{-1}$ after $6 \mathrm{~h}$ of development compared with the parental strain increasing from 0.8 to 22 units (mg protein $)^{-1}$ in the same time period. One unit is the activity producing $1 \mathrm{pmol}$ cyclic AMP $\min ^{-1}$.] It is deduced that the primary lesion of NP160 does not lie in the basal activity of adenylate cyclase but the data are not inconsistent with a fault in the periodic activation of the enzyme needing for signalling.

Signal relay. Evidence that mutant NP160 is deficient in signal relay and autonomous signal generation came from visual observations of starving amoebae placed as lawns at high density $\left(8 \times 10^{5} \mathrm{~cm}^{-2}\right)$ on buffered agar. Under dark-field illumination (Gross et al., 1976) relay may be visualized in the wild-type as bright and dark bands moving outward from the aggregation centres. These bands correspond to cells moving towards the centres (light bands) and stationary cells awaiting the next signal (dark bands) (Alcântara \& Monk, 1974). Under such conditions NP160 produced no bands at all, the cells merely remaining as a randomly moving lawn. When agar blocks bearing amoebae showing moving light and dark bands were cut out of control plates and carefully placed in direct contact alongside blocks bearing NP160, the relayed waves were not continued by the mutant but failed abruptly at the junction of the two blocks. There was some evidence, however, of local chemotactic movement of the NP160 on to the agar with the relaying cells, indicating that the mutant could perceive the signals.

Contact site $A$. No contact sites A were formed during starvation in liquid suspension culture. Contact sites $\mathrm{A}$ are glycoproteins that are formed during starvation and mediate intercellular binding (Beug et al., 1973; Huesgen \& Gerisch, 1975). They are regulated by periodic cyclic AMP signalling during aggregation (Gerisch et al., 1975) and are not formed in the absence of pulsatile signalling. To see if contact sites A could be induced in NP160 by artificial cyclic AMP pulses, cyclic AMP was added at $5 \mathrm{~min}$ intervals to suspensions of the mutant (to a concentration of $100 \mathrm{nM}$ ) over a period of $8 \mathrm{~h}$. Visual inspection clearly demonstrated the presence of cell clusters and chains which were not disrupted by $5 \mathrm{mM}$-EDTA, indicative of contact sites A. Control suspensions of NP160 without cyclic AMP pulses showed only single cells. It is deduced that NP160 is only able to form contact sites with the aid of artificial pulses and we infer that such cyclic AMP pulses are normally lacking in the mutant.

Mutant NP160 is, therefore, an excellent mutant for use in experiments designed to test the capacity of the wild-type strain to initiate aggregation. It is unable to initiate or relay pulses of cyclic AMP itself but can respond to signals from the wild-type with a normal chemotactic response and form fruiting bodies. It is able to receive and process cyclic AMP signals with a 


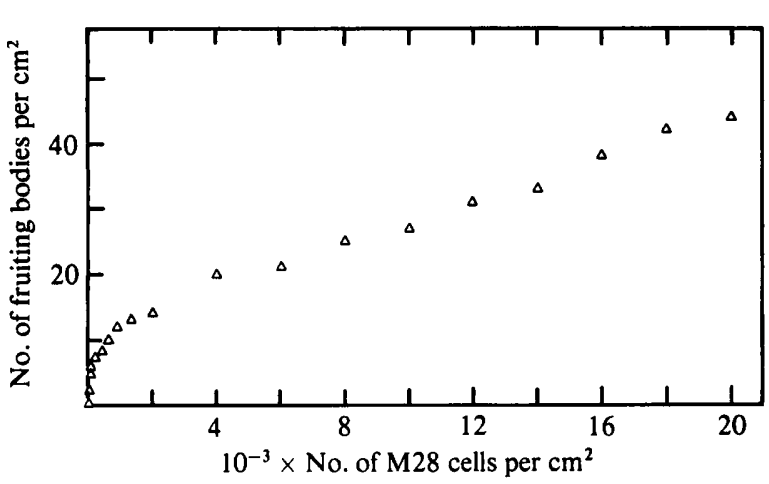

Fig. 7

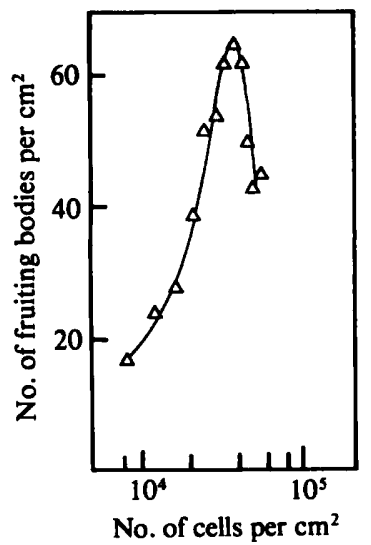

Fig. 8

Fig. 7. Number of fruiting bodies formed in mixtures of wild-type strain M28 and mutant NP160 on non-nutrient agar chips. The total cell density was kept at $2 \times 10^{4} \mathrm{~cm}^{-2}$ but the relative density of the two strains was varied from one extreme to the other.

Fig. 8. Number of fruiting bodies formed by homogeneous populations of wild-type strain M28 on non-nutrient agar chips at $22^{\circ} \mathrm{C}$. Note that at a cell population density above $4 \times 10^{4} \mathrm{~cm}^{-2}$ the number of fruiting bodies formed sharply declined. This point represents the critical density at which cells are close enough for signal relay to operate and thereby cause an increase in the size of the aggregation territory.

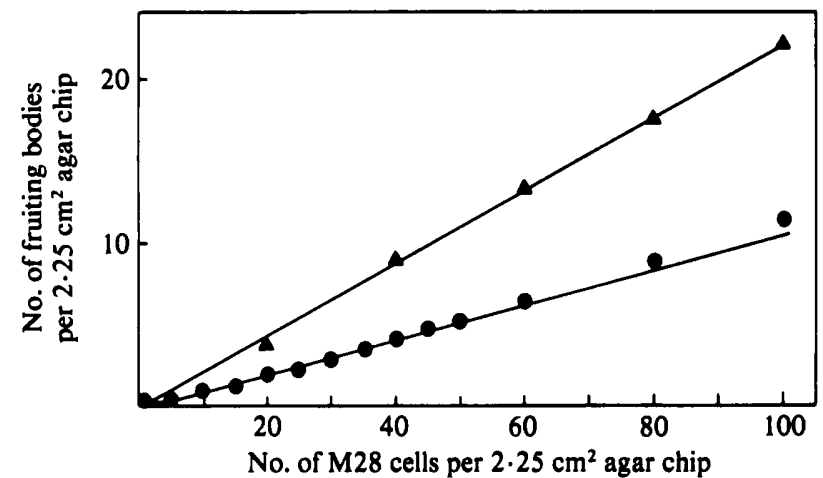

Fig. 9. Number of fruiting bodies formed in synergistic mixtures of wild-type strain M28 and mutant NP160 on non-nutrient agar chips in the absence $(O)$ and presence $(\Delta)$ of $10 \mathrm{mM}$-L-histidine. The data represent the mean of six experiments. The number of NP160 cells was kept at $2 \times 10^{4} \mathrm{~cm}^{-2}$ and the number of M28 cells was varied from 0 to $50 \mathrm{~cm}^{-2}$. The number of $\mathrm{M} 28$ cells plated was determined by careful serial dilution of suspensions dense enough to be counted in a haemocytometer and then checked by plating samples of the diluted suspension on to lawns of $K$. aerogenes to determine viable counts.

sensitivity that would enable it to respond to weak signals from low numbers of wild-type amoebae.

\section{Ability of the wild-type to form aggregation centres in mixtures with mutant NP160}

The ability of strain M28 to initiate aggregation centres was tested using starving mixed populations of M28 and NP160 amoebae on non-nutrient agar. The number of fruiting bodies formed by such mixtures was assessed under the strictly standardized conditions outlined in Methods. The total population per agar chip was kept at $4.5 \times 10^{4}\left(\right.$ i.e. $\left.2 \times 10^{4} \mathrm{~cm}^{-2}\right)$ and the 
ratio of the strains was varied from one extreme to the other. The results (Fig. 7) indicate that the number of fruiting bodies formed was dependent on the number of M28 amoebae present. It was also noticeable that with increasing numbers there was substantial competition among M28 amoebae in the formation of these centres. This competition, however, was not due to signal relay as the highest concentration of M28 cells used $\left(2 \times 10^{4} \mathrm{~cm}^{-2}\right)$ was below the critical threshold needed for signal relay (Fig. 8) as determined by the method of Gingle \& Robertson (1976). This competition decreased the apparent efficiency of centre formation by the M28 cells to approximately 1 centre for every 1000 M28 cells plated. To overcome this competitive effect, further experiments were carried out to look at the number of fruiting bodies formed in mixed populations containing very few M28 cells (between 2 and 50 cells $\mathrm{cm}^{-2}$ ) (Fig. 9). With so few wild-type cells, the number of aggregates varied linearly with the number of M28 cells plated, presumably because the M28 cells were too sparsely spread for competitive interactions to occur. Under such conditions it may be calculated from the slope of the graph that 1 fruiting body was formed for every $10 \mathrm{M} 28$ cells present.

Whether or not an M28 cell triggers chemotaxis and aggregation by nearby NP160 cells must depend on the excitability of the M28 cell and on the sensitivity of the responding NP160 cells. In an attempt to increase this sensitivity, a number of agents were added to the agar. Over a wide range of concentrations $\mathrm{Ca}^{2+}$ had no apparent effect, while phosphodiesterase (from beef heart) caused only a marginal increase in the number of fruiting bodies produced by the synergistic mixtures. However, when L-histidine, which was shown by Bradley et al. (1956) to stimulate aggregation, was added to the agar, a marked increase in the number of fruiting bodies produced by the synergistic mixtures was observed (Fig. 9), the slope of the graph indicating that under these conditions 1 in 5 of the M28 cells was initiating fruiting body formation.

\section{DISCUSSION}

Previous attempts at finding the number of cells in an amoebal population that could initiate aggregation either used homogeneous populations containing several thousand cells and found initiators at a frequency of roughly 1 in 2000 , or used small drop populations of 100 to 200 cells and found initiators at a frequency of roughly 1 in 100 . It is clear from the present study, however, that substantial competition for centre formation arises with populations containing more than 100 cells $\mathrm{cm}^{-2}$ and as a consequence only minimal estimates for centre-forming ability may be made in such studies. On the other hand, populations of much less than 100 wild-type cells on agar do not consistently initiate aggregates. The present study obviated this dilemma by using very small numbers of wild-type cells mixed with a large population of a mutant that was itself unable to initiate centres.

Most aggregation mutants would have been unsuitable for such a study as they either do not interact to produce fruiting bodies at high frequency in mixtures with the wild-type, or they fail to produce components of the chemosensory apparatus (such as phosphodiesterases) that ensure high sensitivity to signals produced by wild-type cells present in population ratios of only 1 in 10000 . Mutant NP160 was found to show unusually high synergism with the wild-type and detailed studies of its genetics and biochemical abilities revealed that it possessed a mutation on linkage group IV that prevented it from initiating or relaying cyclic AMP signals in the aggregation phase but that in other important respects it appeared normal. It grew with the vigour of the wild-type and for the first $8 \mathrm{~h}$ of aggregation it produced cell-surface cyclic AMP receptors, cyclic AMP and extracellular and membrane-bound phosphodiesterases in amounts similar to the parental strain. It showed normal chemotactic ability in artificial cyclic AMP gradients and, as would be expected for such a mutant lacking signal initiation, contact sites A were not formed in the absence of artificial cyclic AMP pulses. Its properties, therefore, made it highly suitable as a synergistic partner 
for testing the initiative ability of the wild-type present at low frequency, and in a wider context it should prove valuable for other studies requiring a mutant with these unusual characteristics.

Synergism tests of strains NP160 and M28 showed that when as few as 2 cells $\mathrm{cm}^{-2}$ (5 cells per $2.25 \mathrm{~cm}^{2}$ agar chip) were present, M28 could initiate aggregation and fruiting body formation in NP160. The ratio of initiation of M28 (found over the range 2 to 50 cells $\mathrm{cm}^{-2}$ ) was 1 cell in 10 on standard buffered agar and 1 cell in 5 when the sensitivity of the responding amoebae was raised by adding $10 \mathrm{mM}$-L-histidine to the buffered agar. Although this does not show that every M28 is capable of initiation, the finding that 1 in 5 of the population have that capability makes it extremely unlikely that a special subset of initiator cells is responsible for initiating aggregation. If such a subset existed it would comprise $20 \%$ of the population even during the growth phase, with the probability that, under most conditions, only 1 cell in 200 of the subset would be needed and used for initiation. Since such a large subpopulation does not have genetic or phenotypic characteristics that have been reported, its existence seems highly unlikely, and we suggest that the data presented is strong evidence that initiator cells are not a pre-existing cell type but arise from the starving population of amoebae during the phase of aggregation.

We wish to thank our colleagues Drs Fiona Ross, Jim Grutsch, Barrie Coukell, Ms Ann Cameron and Ms Jeannie Wallace for help of many kinds, Mr Frank Caddick for photography and drawing the figures and Mrs Patricia Stallard for typing the manuscript.

\section{REFERENCES}

Alcântara, F. \& Monk, M. (1974). Signal propagation during aggregation in the slime mould Dictyostelium discoideum. Journal of General Microbiology 85, 321-334.

Beug, H., Katz, F. E. \& Gerisch, G. (1973). Dynamics of antigenic membrane sites relating to cell aggregation in Dictyostelium discoideum. Journal of Cell Biology 56, 647-658.

BONNER, J. Y., BARKLEY, D. S., Hall, E. M., KoniJN, T. M., Mason, J. W., O'Keefe, G. \& Wolfe, P. B. (1969). Acrasin, acrasinase and the sensitivity to acrasin in Dictyostelium discoideum. Developmental Biology 20, 72-87.

Bradley, S. G., Sussman, M. \& ENNIS, H. L. (1956). Environmental factors affecting the aggregation of the cellular slime mold Dictyostelium discoideum. Journal of Protozoology 3, 33-38.

Coukell, M. B. \& Chan, F. K. (1980). The precocious appearance and activation of an adenylate cyclase in a rapid developing mutant of Dictyostelium discoideum. FEBS Letters 110, 3942.

Darmon, M., Barrand, P., Brachet, P., Klein, C. \& Pereira dA Silva, L. (1977). Phenotypic suppression of morphogenetic mutants of Dictyostelium discoideum. Developmental Biology 58, 174-184.

ENNIS, H. L. \& SUSSMAN, M. (1958a). The initiator cell for slime mold aggregation. Proceedings of the National Academy of Sciences of the United States of America 44, 401-411.

ENNIS, H. L. \& Sussman, M. (1958b). Synergistic morphogenesis by mixtures of Dictyostelium discoideum wild-type and aggregateless mutants. Journal of General Microbiology 18, 433-449.
GERISCH, G. (1961). Zellfunktionen und Zellfunktionswechsel in der Entwicklung von Dictyostelium discoideum. Developmental Biology 3, 685-724.

GERISCH, G. \& HESS, B. (1974). cAMP-controlled oscillations in suspended Dictyostelium cells: their relation to morphogenetic cell interactions. Proceedings of the National Academy of Sciences of the United States of America 71, 2118-2122.

Gerisch, G., Fromm, H., Huesgen, A. \& Wick, U. (1975). Control of cell-contact sites by cyclic AMP pulses in differentiating Dictyostelium cells. Nature, London 255, 547-549.

Gingle, A. R. \& Robertson, A (1976). The development of the relaying competence in Dictyostelium discoideum. Journal of Cell Science $\mathbf{2 0}$, 21-27.

Green, A. A. \& Newell, P. C. (1975). Evidence for the existence of two types of cAMP binding sites in aggregating cells of Dictyostelium discoideum. Cell 6, 129-136.

Gross, J. D., Peacey, M. J. \& Trevan, D. J. (1976). Signal emission and signal propagation during early aggregation in Dictyostelium discoideum. Journal of Cell Science 22, 645-656.

HuEsGen, A. \& Gerisch, G. (1975). Solubilized contact sites A from cell membranes of Dictyostelium discoideum. FEBS Letters 56, 46-49.

JuLIANI, M. H. \& KLEIN, C. (1978). A biochemical study of the effects of cAMP pulses on aggregateless mutants of Dictyostelium discoideum. Developmental Biology 62, 162-172.

Katz, E. R. \& Sussman, M. (1972). Parasexual recombination in Dictyostelium discoideum: selection of stable diploid heterozygotes and stable haploid segregants. Proceedings of the National 
Academy of Sciences of the United States of America 69, 495-498.

KoniJn, T. M. \& RAPER, K. B. (1961). Cell aggregation in Dictyostelium discoideum. Developmental Biology 3, 725-756.

Malchow, D., Nagele, B., Schwarz, H. \& Gerisch, G. (1972). Membrane-bound cyclic AMP phosphodiesterase in chemotactically responding cells of Dictyostelium discoideum. European Journal of Biochemistry 28, 136-142.

Mosses, D., Williams, K. L. \& Newell, P. C. (1975). The use of mitotic crossing-over for genetic analysis in Dictyostelium discoideum: mapping of linkage group II. Journal of General Microbiology 90, 247-259.

Mullens, 1. A. \& Newell, P. C. (1978). cAMP binding to cell surface receptors of Dictyostelium. Differentiation 10, 171-176.

RAMAN, R. K. (1976). The autonomous cell in Dictyostelium discoideum. Journal of Theoretical Biology 59, 491-495.

Raman, R. K., Hashimoto, Y., Cohen, M. H. \& Robertson, A. (1976). Differentiation for aggregation in the cellular slime moulds: the emergence of autonomously signalling cells in Dictyostelium discoideum. Journal of Cell Science 21, 243-259.

RAPER, K. B. (1935). Dictyostelium discoideum, a new species of slime mold from decaying forest leaves. Journal of Agricultural Research 50, 135-147.

RATNER, D. I. \& Newell, P. C. (1978). Linkage analysis in Dictyostelium discoideum using multiply marked tester strains: establishment of linkage group VII and the reassessment of earlier linkage data. Journal of General Microbiology 109, 225-236.

Ross, F. M. \& Newell, P. C. (1979). Genetics of aggregation pattern mutations in the cellular slime mould Dictyostelium discoideum. Journal of General Microbiology 115, 289-300.

Ross, F. M. \& Newell, P. C. (1981). Streamers: chemotactic mutants of Dictyostelium with altered cyclic GMP metabolism. Journal of General Microbiology 127 (in the Press).

SusSmaN, M. (1952). An analysis of the aggregation phase in the development of the slime molds Dictyosteliaceae. II, Aggregative centre formation by mixtures of Dictyostelium discoideum wild type and aggregateless variants. Biological Bulletin 103, 446-457.

Sussman, M. \& NoEl, E. (1952). An analysis of the aggregation phase in the development of the slime molds Dictyosteliaceae. I, Population distribution of the capacity to initiate aggregation. Biological Bulletin 103, 259-268.

Williams, K. L. \& Newell, P. C. (1976). A genetic study of aggregation in the cellular slime mould Dictyostelium discoideum using complementation analysis. Genetics 82, 287-307.

Williams, K. L., Kessin, R. H. \& Newell, P. C. (1974). Parasexual genetics in Dictyostelium discoideum: mitotic analysis of acriflavin resistance and growth in axenic medium. Journal of General Microbiology 84, 59-69. 